\title{
On the involvement of prefrontal networks in cognitive ageing
}

Citation for published version (APA):

Tisserand, D. J., \& Jolles, J. (2003). On the involvement of prefrontal networks in cognitive ageing. Cortex, 39(4-5), 1107-1128. https://doi.org/10.1016/S0010-9452(08)70880-3

Document status and date:

Published: 01/01/2003

DOI:

10.1016/S0010-9452(08)70880-3

\section{Please check the document version of this publication:}

- A submitted manuscript is the version of the article upon submission and before peer-review. There can be important differences between the submitted version and the official published version of record.

People interested in the research are advised to contact the author for the final version of the publication, or visit the DOI to the publisher's website.

- The final author version and the galley proof are versions of the publication after peer review.

- The final published version features the final layout of the paper including the volume, issue and page numbers.

Link to publication

\footnotetext{
General rights rights.

- You may freely distribute the URL identifying the publication in the public portal. please follow below link for the End User Agreement:

www.umlib.nl/taverne-license

Take down policy

If you believe that this document breaches copyright please contact us at:

repository@maastrichtuniversity.nl

providing details and we will investigate your claim.
}

Copyright and moral rights for the publications made accessible in the public portal are retained by the authors and/or other copyright owners and it is a condition of accessing publications that users recognise and abide by the legal requirements associated with these

- Users may download and print one copy of any publication from the public portal for the purpose of private study or research.

- You may not further distribute the material or use it for any profit-making activity or commercial gain

If the publication is distributed under the terms of Article $25 \mathrm{fa}$ of the Dutch Copyright Act, indicated by the "Taverne" license above, 


\title{
SPECIAL ISSUE \\ ON THE INVOLVEMENT OF PREFRONTAL NETWORKS IN COGNITIVE AGEING
}

\author{
Danielle J. Tisserand ${ }^{1}$ and J. Jolles ${ }^{2}$ \\ $\left({ }^{1}\right.$ Rotman Research Institute, Baycrest Centre for Geriatric Care, Toronto, Canada; ${ }^{2}$ Brain \\ and Behaviour Institute, Maastricht University, The Netherlands)
}

\begin{abstract}
Normal ageing is associated with a wide variety of disturbances in the structure and function of the human brain. Recent neuroimaging studies suggest that the prefrontal cortex (PFC) is particularly vulnerable to the effects of ageing. These findings are compatible with the so-called 'frontal ageing hypothesis' which has been formulated on the basis of neuropsychological research on non-pathological ageing. We will argue on the basis of recent structural and functional neuroimaging studies that this hypothesis needs to be refined, especially to acknowledge the possible relevance of a distinction between subregions within the PFC. In addition, findings with regard to a differential involvement of grey versus white matter suggest that both have to be considered in relation to agerelated cognitive decline. Hence, neural networks and larger systems of interconnected brain regions and the functional activity in these circuits may be more important than specific cortical regions to explain age effects on cognitive functioning. Finally, it is important to consider individual variability due to sex differences and age-extrinsic biomedical factors in research which examines the relationship between brain structure or function and cognitive ageing.
\end{abstract}

Key words: neuroimaging, prefrontal cortex, medial temporal lobe, functional connectivity, aging, human

\section{INTRODUCTION}

It has been known for long from postmortem research that human ageing is accompanied by a reduction in brain volume (e.g., Haug, 1985; Kemper, 1994; Morrison and Hof, 1997; Uylings et al., 2000). Until recently, this atrophy was thought to be the consequence of neuronal loss (Kemper, 1994). However, with the aid of more modern tools it has been shown that the reduction in total neuronal number is only slight, and atrophy may be rather the result of cell shrinkage, dendritic regression, and a reduction in synaptic density (Haug, 1985; Uylings et al., 2000). The functional significance of these neuronal changes is unclear. At present, there is no direct evidence for a relationship between regional neuronal number and cognitive performance in non-pathological ageing (e.g., Uylings et al., 2000).

Nevertheless, because cognitive processes are dependent upon the integrity of the brain, it does seem likely that changes in brain morphology and/or brain functioning can (partly) account for age-related decreases in cognitive functioning. The neural basis of human cognitive ageing has gained increasing

Cortex, (2003) 39, 1107-1128 
interest since it became possible to study the structure and function of the brain in vivo, using techniques such as computerized tomography (CT), magnetic resonance imaging (MRI), and positron emission tomography (PET).

In this paper we will provide an update of the most recent neuroimaging literature on structural and functional changes in normal, non-pathological brain ageing, while specifically focusing on those regions involved in cognitive functioning. We will put forward the view that cognitive changes in normal, nonpathological ageing are particularly associated with alterations within the prefrontal cortex (PFC). This hypothesis has been proposed since the eighties (e.g., Jolles, 1986; Moscovitch and Winocur, 1995; West, 1996; Phillips and Della Sala, 1999; Braver et al., 2001). However, recent findings suggest that the 'frontal ageing hypothesis' needs to be refined. We will elaborate on this notion by hypothesizing that: (1) age-related brain changes are greatest in specific subregions within the PFC and the neural circuits they are part of, (2) not only grey but also white matter integrity is of major importance for adequate cognitive functioning, and (3) a reduction in 'strategic' information processing capacity, subserved by this prefrontal circuitry, is greatly responsible for age-related cognitive impairments. Furthermore, there is substantial heterogeneity in cognitive ageing trajectories, and a distinction can be made between 'successful' and 'usual' ageing (Rowe and Kahn, 1987). Therefore, we will critically evaluate factors which may possibly modulate the association between brain, ageing and cognition.

\section{Brain Ageing: Structural Neuroimaging}

\section{The Limbic-Diencephalic System}

In accordance with postmortem studies, neuroimaging research has consistently shown that the total brain volume decreases as a function of age (e.g., Jernigan et al., 1991, 2001; Coffey et al., 1992, 1998; Pfefferbaum et al., 1994; Blatter et al., 1995; Raz et al., 1997; Courchesne et al., 2000; Resnick et al., 2000; Tisserand et al., 2000b). Just as age effects are not uniform across cognitive functions, regional differences in structural decline of the ageing brain have been found. Because numerous neuropsychological studies have emphasized agerelated deterioration of memory processes (e.g., Jolles, 1986; Craik and Jennings, 1992; Verhaeghen et al., 1993; Moscovitch and Winocur, 1995; Prull et al., 2000), the majority of neuroimaging research has focused on the neural substrate of memory. A number of brain regions, together making up the limbic-diencephalic network, play a key role in learning and memory. These include the hippocampal system, parahippocampal gyrus, anterior cingulate, medial thalamus, and mammillary bodies (Zola-Morgan and Squire, 1993; Petri and Mishkin, 1994). Atrophy of the hippocampus and related structures is consistently found in pathological ageing (e.g., De Leon et al., 1989; Fox et al., 1996; Kaye et al., 1997; Jack et al., 1992, 1998, 1999; Visser et al., 1999; Laakso et al., 2000). Also in many studies on normal ageing, a reduction in hippocampal and parahippocampal volume has been found (Murphy et al., 1996; De Leon et al., 1997; Raz et al., 1997; Jack et al., 1992, 1998; Mueller et al., 1998; Tisserand et al., 2000b; 
Ylikoski et al., 2000; Pruessner et al., 2001). However, several other studies did not find evidence for age-related volume losses in the hippocampus (Lim et al., 1990; Sullivan et al., 1995; Bigler et al., 1997), or reported that the decrease was not disproportional when compared to tissue loss in other brain regions ( $\mathrm{Raz}$ et al., 1997; Tisserand et al., 2000b). Most of these studies have been cross-sectional and therefore provide only indirect evidence for age-related atrophy. Several studies found a significant longitudinal decrease in medial temporal lobe (MTL) volume in individuals over 65 years of age (Kaye et al., 1997; Jack et al., 1998; Mueller et al., 1998), whereas in two studies in adult subjects across the age range, no evidence was found for longitudinal changes in the volume of the temporal lobes as a whole (Pfefferbaum et al., 1998; Resnick et al., 2000).

Whereas age effects on MTL regions have been fairly well documented, only a small number of studies have focused on other limbic-diencephalic structures, with conflicting results. A significant reduction in the volume of the thalamus has been reported by some (Murphy et al., 1996; Van der Werf et al., 2001), but not by others (Jernigan et al., 1991, 2001). Likewise, while we found an age-related decrease in anterior cingulate volume (Tisserand et al., 2001, 2002), others did not (Jernigan et al., 1991; Raz et al., 1997). Finally, with respect to the volume of the mammillary bodies, age-related losses have been found in some studies (Raz et al., 1992; Sullivan et al., 1999), but not in others (Tisserand et al., 2000a).

Several studies with healthy elderly subjects have tried to relate these reductions in limbic-diencephalic volume to cognitive performance, with mixed results. For instance, one research group found that hippocampal volume was predictive of performance on word list recall (Golomb et al., 1994) and subsequent decline on memory tests after a period of four years (Golomb et al., 1996), while others failed to find a relationship with test performance after adjusting for age effects (Raz et al., 1998; Petersen et al., 2000; Tisserand et al., 2000b; Ylikoski et al., 2000) or even found an inverse relationship (Köhler et al., 1998; Foster et al., 1999). Interestingly, one study found an age-independent correlation between thalamic volume and speed of information processing (but not memory functioning) in young but not in older subjects (Van der Werf et al., 2001). This suggests that in healthy young adults, larger thalamic volume may be favourable for fast processing of information, while variance in volume associated with increasing age is not predictive of task performance. Perhaps in elderly subjects, volume decreases are linked to cognitive deterioration only when pathological mechanisms are involved (DeCarli et al., 1994; Köhler et al., 1998; Foster et al., 1999; Kabani et al., 2002). Alternatively, a lack of associations between brain volume and performance in older subjects may be due to an increase in the variance of these measures with age (e.g., Blatter et al., 1995; Jernigan et al., 2001). This differential influence of age on the direction of brain-behaviour associations may explain why most studies with subjects across the adult age range have not found an effect of brain volume on cognitive performance.

\section{The Frontal-Striatal-Thalamic System}

Studies involving patients with focal brain damage (e.g., Janowsky et al., 1989; Stuss et al., 1994; Shimamura et al., 1995) and neuroimaging experiments 
with healthy individuals (e.g., Tulving et al., 1994; Kapur et al., 1996; Smith et al., 1996; reviewed by Fletcher and Henson, 2001) suggest that frontal regions may play an equally important role as the limbic system in certain memory domains, especially those involving active organization of the memory contents. The frontal cortex plays a crucial role in a second cognitive brain circuit, which is designated the frontal-striatal-thalamic network (Alexander et al., 1990; Cummings, 1993; Rubin, 1999). This network actually consists of five parallel circuits, three of which are involved in complex behaviour and cognition, such as working memory and executive functions. These circuits typically include a region within the frontal lobes, projecting to striatal structures, which are connected through the globus pallidus and substantia nigra to the thalamus. This structure in turn projects back to the frontal regions (Alexander et al., 1990; Cummings, 1993). In comparison to the literature on limbic-diencephalic structures, reports on age-related changes within the frontal-striatal circuit are relatively limited in number. Nonetheless, there is evidence for disproportionate volume losses within the frontal lobes (Coffey, 1993; Cowell et al., 1994; Raz et al., 1997; Salat et al., 1999, 2001; Tisserand et al., 2001, 2002), the thalamus (Van der Werf et al., 2001) and the striatum (Gunning-Dixon et al., 1998; Rubin, 1999). In an extensive review of the literature on correlations between regional cerebral volume and age, Raz (2000) found that the brain regions most affected are the PFC and the striatum (caudate and putamen). Longitudinally, the cortical region with the greatest volume reduction over a 5-year period was found to be the PFC (Pfefferbaum et al., 1998). Unfortunately, no subcortical grey matter structures (such as the striatum or thalamus) were measured in this study.

Only few studies examined the association between atrophy in this circuit and cognitive decline. A weak relation was found between prefrontal volume and working memory performance (Raz et al., 1998), and cognitive flexibility (Hänninen et al., 1997), but this association was no longer significant when age effects were adjusted for (Raz et al., 1998). As mentioned earlier, in young individuals, the volume of the thalamus was found to be predictive for processing speed (Van der Werf et al., 2001).

\section{White Matter Changes}

Whereas an age-related decline in regional grey matter volume has been observed in most imaging studies (Jernigan et al., 1991, 2001; Pfefferbaum et al., 1994; Blatter et al., 1995; Raz et al., 1997; Courchesne et al., 2000; Resnick et al., 2000), starting already in young adults (Blatter et al., 1995; Gur et al., 1999; Courchesne et al., 2000), there is still debate as to the relative contribution of white matter to volume decreases in ageing. Postmortem findings have suggested that white matter atrophy is even more extensive than grey matter loss (e.g., Kemper, 1994). Likewise, several MRI studies have reported age-related loss of white matter (Guttmann et al., 1998; Resnick et al., 2000; Jernigan et al., 2001), especially in the frontal lobes (Raz et al., 1997; Salat et al., 1999; Jernigan et al., 2001). However, other imaging studies have not found evidence for global white matter volume decreases (Jernigan et al., 1991; Pfefferbaum et 
al., 1994; Blatter et al., 1995; Raz et al., 1997). It has been suggested that white matter volume remains relatively stable until high age, after which a rapid decline occurs (Salat et al., 1999; Tisserand et al., 2002).

Regardless of whether or not the overall white matter volume decreases, it is not to say that no structural changes take place within the white matter with advancing age. In fact, a very prominent feature noted in brain imaging is an age-related increase in white matter lesions: small damaged foci, which nevertheless can be quite readily observed on CT and MRI (e.g., Jernigan et al., 1991, 2001; Boone et al., 1992; Ylikoski et al., 1993; Breteler et al., 1994; DeCarli et al., 1995; Longstreth et al., 1996). White matter lesions have been found to co-occur with, and to be even more common than, grey matter atrophy (Ylikoski et al., 2000; Jernigan et al., 2001). These lesions are associated with cognitive deficits and may be implicated in the age-related decline in cognitive performance (Longstreth et al., 1996; Gunning-Dixon and Raz, 2000). The associations between severity of the lesions and cognitive decline are particularly evident on tests measuring attention and processing speed (e.g., Boone et al., 1992; Ylikoski et al., 1993; DeCarli et al., 1995; De Groot et al., 2000). Little is known about regional specificity, although there is some evidence that white matter lesions are most frequent in the frontal lobes (De Leeuw et al., 2001; Jernigan et al., 2001).

Other evidence for an age-related decrease in white matter integrity comes from MRI studies which have used diffusion tensor imaging (DTI). DTI is a recently developed technique which provides an index of microstructural tissue properties by assessing the orientation of diffusion of water molecules within the white matter (Pierpaoli et al., 1996). A reduction in this diffusion tensor (implying a disruption of the white matter tracts) has been found with advancing age (Nusbaum et al., 2001; O'Sullivan et al., 2001; Sullivan et al., 2001; Abe et al., 2002), with the strongest effects within the frontal white matter ( O'Sullivan et al., 2001; Sullivan et al., 2001; Abe et al., 2002). Together with the increase in white matter lesions, these findings of changes in the organisation of white matter pathways in normal ageing have been interpreted in terms of increased vulnerability of older individuals for cognitive dysfunction due to (sub)cortical disconnection.

\section{Conclusion}

To summarize, ageing is associated with decreased grey matter volume, and the volume reductions are greatest for the frontal lobes, striatum, and thalamus. On the other hand, changes within the limbic-diencephalic memory system appear to be relatively mild. Age-related changes within the white matter have also been observed, particularly as an increase of white matter lesions, with the highest frequency in the frontal lobes. As the grey matter structures mentioned are strongly interconnected, it is plausible that volume losses within the frontalstriatal-thalamic circuit may contribute to age-related cognitive decline. Generally, however, volume decreases within grey matter structures have not been found to be predictive of deterioration in specific cognitive functions. On the other hand, lesions within the white matter have been associated with aspecific dysfunctions 
such as reduced information processing speed and attention. As the white matter contains the fibers which connect the various cortical and subcortical grey matter structures, these white matter lesions may disrupt the neural transmission in functional networks, resulting in performance decreases.

\section{Brain Ageing: Functional Neuroimaging}

\section{General Findings in Neuroimaging Studies}

The fact that only few associations have been found between structural brain changes and cognitive performance in normal ageing, may be due to the fact that changes in brain structure as such do not have a straightforward relation with brain function. A more direct way to link brain and behaviour is by using functional imaging methods. In contrast with the large number of studies of age-related structural brain changes, the field of research which investigates functional changes is still relatively young, although the number of publications is increasing rapidly (see for some recent reviews on functional imaging studies and ageing: Cabeza, 2000, 2002; Grady and Craik, 2000; Raz, 2000). In the present paper we will mainly focus on changes within the PFC and the MTL.

Functional neuroimaging studies have examined the effect of age both at rest and during cognitive test performance. At rest, a moderate decrease in both regional cerebral blood flow and metabolic rate has consistently been found, with differential sensitivity of the frontal lobes (Kuhl et al., 1982; De Leon et al., 1987; Leenders et al., 1990; Martin et al., 1991; Loessner et al., 1995; Moeller et al., 1996; Petit-Taboué et al., 1998; Garraux et al., 1999), a pattern which is already evident in middle-aged adults (Schultz et al., 1999). Findings with respect to the MTL are inconsistent, but in general, no disproportionate change in activity has been reported (save by Martin et al., 1991).

The majority of activation studies on ageing have focused on explicit memory and working memory. This is not surprising, given the evidence that age-related cognitive deficits are particularly evident in these domains (Jolles, 1986; Craik and Jennings, 1992; Moscovitch and Winocur, 1992; Verhaeghen et al., 1993; Salthouse, 1996; Parkin and Java, 2000; Prull et al., 2000). Experiments that have examined age-related differences in brain activation patterns during more basic cognitive functions such as visual perception (Grady et al., 1994; Horwitz et al., 1995; Ross et al., 1997), motor function (Calautti et al., 2001), and attention (Johannsen et al., 1997; Madden et al., 1997) are still relatively limited in number. Although in this review we will concentrate on higher cognitive functions, it is important to bear in mind that already at the lowest level of information processing age-related changes occur (due to real functional differences or a lower signal-to-noise ratio in older subjects, e.g., D’Esposito et al., 1999). Because in most functional imaging studies a certain experimental condition is compared to a baseline condition, baseline differences in activation can substantially influence the results of group comparisons. 


\section{Brain Activity and Memory Tasks}

Neuropsychological research has consistently found that working memory capacity, which involves the temporal storage and processing of information, is strongly reduced by increasing age (e.g., Kirasic et al., 1996; Park et al., 1996; Parkin and Java, 2000). During working memory tasks, young individuals tend to activate regions within the lateral and medial prefrontal and posterior parietal cortex, and this activity is asymmetrical depending on the stimulus material. Verbal tasks have been associated with predominantly left-hemisphere activity, whereas spatial tasks elicit mainly activity in the right hemisphere (Smith et al., 1996; Smith and Jonides, 1997; D'Esposito et al., 1998; Reuter-Lorenz et al., 2000). In elderly subjects, this lateralization in frontal regions is less outspoken and bilateral activity patterns during both spatial and verbal working memory tasks occur (Reuter-Lorenz et al., 2000; Cabeza, 2002). Furthermore, apart from such a hemispheric distinction, task-dependent differences in activity in ventrolateral versus dorsolateral PFC have been observed in young subjects (Braver et al., 1997; Cohen et al., 1997; Manoach et al., 1997; Rypma and D'Esposito, 1999; Stern et al., 2000). According to the so-called two-stage model of working memory, the ventrolateral PFC is principally concerned with maintaining information in working memory, while the dorsolateral PFC is recruited when active manipulation of the stored items is required (Petrides, 1995; Owen et al., 1996, 1998). Because elderly are more impaired on tasks which require manipulation and executive control than those requiring only temporal storage in working memory (as reviewed by Verhaeghen et al., 1993), one might expect the greatest age-related differences in brain activity to be located within the dorsolateral PFC. Indeed, whereas task-related activity was noted both in dorsolateral and ventrolateral PFC across groups, an age-related difference in activation during various working memory tasks was found in the dorsolateral but not ventrolateral PFC (Nagahama et al., 1997; Esposito et al., 1999; Rypma and D'Esposito, 2000). In the experiment by Rypma and D'Esposito (2000) the effects of ageing on the various stages of working memory (encoding, storage, and retrieval) were explicitly investigated. Differences between young and older subjects were found only at the retrieval stage, i.e. older individuals activated the dorsolateral PFC to a lesser degree. Other studies, however, did not find evidence for such a differential age effect on the dorsolateral PFC (Grady et al., 1998a; Mencl et al., 2000; Mitchell et al., 2000). Interestingly, in each of these latter reports an age-related difference was instead consistently observed in (the anterior part of) the ventrolateral PFC, as well as in the MTL, areas which the older subjects activated to a lesser degree than the young, or did not activate at all. To conclude, there is conflicting evidence as to whether ageing reduces task-related activity in specific regions within the PFC.

Apart from a working memory decline, a considerable age-related deterioration can also be observed on tasks measuring explicit memory, i.e. the conscious recollection of past events and facts (Graf and Schacter, 1985). A number of studies have considered age-related changes in brain activity on explicit memory tasks. PET and fMRI experiments have shown that in young 
subjects, encoding tasks (either verbal or nonverbal) generally elicit left prefrontal, bilateral medial temporal and fusiform gyrus activation (e.g., Kapur et al., 1996; Nyberg et al., 1996a; Fletcher et al., 1998; Kopelman et al., 1998). The most consistent difference between young and older adults during encoding has been found in prefrontal activity. Older subjects either fail to activate the left frontal cortex (Grady et al., 1995), or exhibit reduced activity (Cabeza et al., 1997a, b; Grady et al., 1998b; Anderson et al., 2000). Findings with regard to age effects on posterior brain regions are less consistent. Medial temporal areas have been reported to be equally (Schacter et al., 1996; Madden et al., 1999), or less (Grady et al., 1995) activated during encoding in elderly.

Whereas during encoding prefrontal activity is mostly left-lateralized, the opposite hemisphere is activated during retrieval, a pattern described as the hemispheric encoding/retrieval asymmetry, HERA (Tulving et al., 1994). Other regions involved in retrieval include the anterior cingulate, medial temporal and parietal lobes, and the cerebellum (e.g., Andreasen et al., 1995; Nyberg et al., 1996b; Rugg et al., 1997; Schacter et al., 1997; Wagner et al., 1998). Again, older adults differ from their younger counterparts particularly in prefrontal activity, that is, they show a more bilateral activation pattern (Schacter et al., 1996; Cabeza et al., 1997a, b; Madden et al., 1999; Anderson et al., 2000; Cabeza, 2002). With respect to the MTL, generally, no age-related difference in activity has been reported (Schacter et al., 1996; Madden et al., 1999; Cabeza et al., 2000; but see Bäckman et al., 1997).

\section{Brain Activity and Effortful Tasks}

How can we interpret these findings, in particular, how can we explain the fact that prefrontal activity in elderly has been found to be decreased under some circumstances (e.g., Grady et al., 1995) and increased under other (e.g., Madden et al., 1999)? One explanation for age-related differences in left prefrontal activity is that it reflects recruitment of additional resources to cope with task demands, i.e. extra effort. That is, when task difficulty increases, an increase in prefrontal activation is likely to occur. This pattern has been found in studies with young subjects, using both working memory (Braver et al., 1997; Manoach et al., 1997; Rypma and D'Esposito, 1999; Tisserand et al., 2000a) and episodic memory tasks (as reviewed by Nolde et al., 1998). Moreover, practice (i.e., a decrease of conscious processing) has been associated with a decrease in frontal activity (Raichle et al., 1994; Garavan et al., 2000; Jansma et al., 2001). This 'prefrontaleffort hypothesis' may also apply to older individuals. On the neural level, it has been described in terms of compensation: by recruiting additional prefrontal regions older adults may prevent their performance from declining (e.g., Grady et al., 1994; Cabeza et al., 1997a; Grady, 2000; Mencl et al., 2000; Cabeza, 2002). This view is supported by a study by Anderson et al. (2000), who found that left prefrontal activity was reduced similarly by ageing and by a divided attention task, suggesting that increasing age and effortful cognitive processing put an equal claim on the available attentional resources. Furthermore, in a study which compared performance on a dual-task with performance on either task alone (Smith et al., 2001) it was found that both older subjects and young poor 
performers activated the left PFC during a demanding dual-task, whereas young good performers did not. Additional evidence for the effort hypothesis comes from an experiment which compared a simple (recognition) and difficult (temporal order) retrieval task (Cabeza et al., 2000). It was found that during the difficult task version young subjects activated the right PFC more than the left, whereas the older subjects had stronger activity in the left PFC. No age differences were found in posterior regions. A final source of evidence for the effort hypothesis is the finding that reduced frontal activity is often accompanied by poorer task performance and/or longer reaction times in older subjects (Grady et al., 1998a; Madden et al., 1999; Grady and Craik, 2000; but see Rypma and D'Esposito, 2000). These findings support the view that older adults make an extra effort to perform as well as young subjects on cognitive tasks, and this is reflected on the functional level as an increase in (left) prefrontal activity.

An alternative (albeit not incompatible) explanation is that age-related changes in frontal activity are part of a more general reduction in the efficiency of neural circuits, and recruitment of brain areas which are not essential to the task (e.g., Cabeza et al., 1997a; Esposito et al., 1999; Madden et al., 1999; McIntosh et al., 1999). This reduced neural efficiency has been ascribed to a decline in frontal inhibitory control over posterior brain regions (Hasher and Zacks, 1988; Esposito et al., 1999; Grady, 2000; Cabeza, 2002). For instance, whereas young individuals were found to recruit a network in which there was strong inhibitory feedback from frontal to posterior regions during a short-term memory task, older subjects' neural connections were much weaker and hardly displayed such inhibitory influences (Della-Maggiore et al., 2000). According to this 'decreased neural efficiency' view, an increase in activity is not necessarily beneficial, as suggested by the effort hypothesis, but rather may be detrimental for cognitive functioning. This interpretation can be tested by relating brain activation patterns to behaviour. Reductions in the efficiency of a given neural circuit may lead to slowing of cognitive processes, which would be reflected as a positive correlation between brain activity and reaction times. Support for this hypothesis comes from a study which showed that in young participants, increases in activity within frontal as well as occipital and medial temporal regions were associated with shorter reaction times, whereas in older adults increased activity in these areas was related to slower performance (Grady et al., 1998a). Other evidence for reduced neural efficiency in the elderly is provided by the study by Madden et al. (1999) in which it was shown that both in young and old subjects, the best predictor of reaction times was a right prefrontal region, while in the old group several additional, non-frontal regions were found to also predict performance.

\section{Conclusion}

In sum, ageing is - generally - accompanied by global decreases in brain activity, both at rest and during cognitive test performance. The most evident changes occur within the PFC. In addition to a general decrease in baseline activation, a particular pattern of task-related activation has been found in elderly, where both decreased and increased frontal activity have been noted. Age effects on brain activity in posterior regions are less clear. An increase in 
frontal activity possibly reflects an extra effort to cope with task demands, whereas a decrease may be related to a reduction in neural efficiency. However, discrepancies between imaging studies remain and no explanation has yet been proposed with respect to sources of variability. The next paragraph is devoted to the evaluation of factors which are possibly important in this respect and which ought to be considered in future studies into the relationship between age, brain, and cognition.

\section{Towards a Differentiation of Age Effects on the Prefrontal Cortex}

\section{Cognitive Differentiation and Neural Networks in Relation to Ageing}

In this paper the main focus has been on age effects in memory-related and higher cognitive functions, i.e., working memory, executive functions, and explicit learning and retrieval. Although age decrements are very prominent on these functions (Jolles, 1986; Craik and Jennings, 1992; Moscovitch and Winocur, 1992; Verhaeghen et al., 1993; Salthouse, 1996; Parkin and Java, 2000; Prull et al., 2000; Braver et al., 2001), these changes cannot be considered in isolation. The role of basic cognitive functions such as processing speed and attention should also be taken into account. These factors have been found to explain a large part of age-related memory deterioration (Verhaeghen et al., 1993; Kirasic et al., 1996; Park et al., 1996; Salthouse, 1996; Earles et al., 1997; Parkin and Java, 2000; Zacks et al., 2000). It has even been suggested (e.g., Salthouse, 1996; Earles et al., 1997) that age-related decline of memory functioning is secondary to reduced processing speed. Reduced information processing speed may explain problems in memory encoding and retrieval because this mental slowing can lead to superficial processing and inefficient strategies where elaboration is required (Jolles, 1986). Interestingly, a strong association between white matter lesions and slowing on information processing tasks in normal, healthy elderly has been found (Ylikoski et al., 1993; DeCarli et al., 1995; De Groot et al., 2000). These results strengthen the notion that the connections between cortical and subcortical regions have to be intact to guarantee the efficiency of the communication between them (e.g., McIntosh, 1999, 2000; Greenwood, 2000; Braver et al., 2001).

The suggestion that it is of importance to adopt a more 'dynamic', and multidimensional view with respect to the relationship between cognitive functioning and regions within the brain has further been stressed in the recent literature. Mesulam (1998) described five brain circuits, each with a different function in information processing and cognition. Basic premise is that cognitive functions are composed of various subprocesses, each requiring the integrity of multiple brain regions. Besides the two networks described earlier in the present paper (designated the explicit memory and working memory-executive function circuits), there are three additional networks involved in spatial awareness, language, and face-object recognition. It is argued that for adequate functioning, activation of each network is required. 'Transmodal nodes' in the brain connect the various circuits, thereby offering a possibility to combine their information. 
Interestingly, there is a model which has applied the idea of such an involvement of multiple brain systems to account for the pattern of cognitive impairments in ageing (Moscovitch and Winocur, 1992, 1995). This model suggests that age does not affect memory per se, but rather influences the capacity to efficiently process information in general. The model distinguishes between two types of explicit memory: associative and strategic. The strategic system consumes more attentional resources than the associative system, and therefore it is more sensitive to an age-related reduction of these resources (Craik and Byrd, 1982). The associative component involves the relatively automatic encoding, storage and retrieval of information and is largely dependent on MTL structures. The more conscious and 'intelligent' control over this automatic, associative system, both at input and output, is provided by the frontal lobes, which are involved in the strategic processing of information (Moscovitch and Winocur, 1992, 1995). This theory offers an explanation for the finding that, although both medial temporal and frontal regions are required for explicit memory, age effects are more pronounced on 'strategic' memory tasks (e.g., free recall), than on tasks that rely primarily on the associative system (e.g., recognition). It also predicts that older individuals are slower and make more errors particularly on demanding cognitive tasks, such as those requiring working memory and executive functions. Finally, this view coincides with the evidence that the integrity of the frontal lobes is more sensitive to ageing than that of the MTL.

It follows from this line of argument that even when the same brain regions are involved in task performance in different age groups, their functional interactions may be different. This finding of altered connectivity in the brains of elderly has been reported many times in neuroimaging experiments with various different paradigms (Grady et al., 1994, 1995; Cabeza et al., 1997a, 1997b; Grady, 1998; Esposito et al., 1999; Madden et al., 1999; McIntosh et al., 1999; Della-Maggiore et al., 2000). For example, an age-related difference in connectivity between the PFC and the MTL has been found (Grady et al., 1995; Esposito et al., 1999; Della-Maggiore et al., 2000). These findings suggest that in order to understand the relation between activity in a given brain region (e.g., PFC) and task performance, the region needs to be considered in the context of other, simultaneously activated and functionally connected, brain areas (McIntosh, 1999; Della-Maggiore et al., 2000; Braver et al., 2001).

\section{Structural Differentiation within the Prefrontal Cortex}

The PFC is a large and heterogeneous region, and can be subdivided in a number of functionally distinct areas. A broad subdivision has been proposed in an orbital, lateral and medial part (Fuster, 1980; Stuss and Benson, 1986; Cummings, 1995). The lateral PFC is thought to be mainly involved in 'higher' cognitive processes such as those related to memory, behavioural planning, and response inhibition. The medial part (especially the anterior cingulate) plays a role in attention and motivation, and the orbital part in emotional and social behaviour, and impulse control (e.g., Cummings, 1995; West, 1996). Recent functional neuroimaging studies suggest that even smaller distinctions should be 
made (e.g., Petrides, 1995; Owen et al., 1996, 1998; Smith and Jonides, 1999; Elliott et al., 2000). For example, as mentioned before, within the lateral PFC a dorsal and ventral part can be distinguished.

It is of relevance in this respect, that each of these prefrontal regions has its own projection areas, and forms a part of a different neural circuit. As mentioned before, all three regions project to the striatum and receive projections from the thalamus. Furthermore, the lateral PFC has reciprocal connections with the orbitofrontal cortex and the anterior cingulate, as well as with posterior association areas and the MTL. The orbitofrontal cortex and anterior cingulate have afferent and efferent connections particularly with the amygdala (Alexander et al., 1990; Cummings, 1995; Petrides, 1995). Despite the fact that such a notion of prefrontal differentiation has been adopted for a number of years, studies which have considered selective structural or functional effects of age on prefrontal subregions are scarce. Ageing may selectively affect particular prefrontal areas while sparing others (Kemper, 1994; Raz et al., 1997; Uylings et al., 2000; Xu et al., 2000; Salat et al., 2001; Tisserand et al., 2001, 2002), and this in turn may have consequences for the specific cognitive functions and networks in which these brain regions are involved. Because of the importance of the PFC in cognitive ageing (e.g., Jolles, 1986; Moscovitch and Winocur, 1995; West, 1996; Phillips and Della Sala, 1999; Braver et al., 2001), future imaging studies have a task in differentiating between frontal regions and their specific functions in relation to ageing.

\section{Subject Selection: the Role of Sex Differences and Age-Extrinsic Factors}

An issue which has received insufficient attention is the difference in brain ageing between men and women. For instance, the rate of global atrophy has been found to be higher for men than for women (Gur et al., 1991, 1999; Blatter et al., 1995; Murphy et al., 1996; Coffey et al., 1998; Xu et al., 2000). Furthermore, there are indications that whereas in men atrophy is especially marked in frontal and temporal regions (Cowell et al., 1994; Murphy et al., 1996; $\mathrm{Xu}$ et al., 2000), in women volume decreases are more pronounced in the parietal lobes and hippocampus (Murphy et al., 1996; Pruessner et al., 2001). However, not all studies have found age-related sex differences in regional brain volumes (e.g., De Leon et al., 1997; Raz et al., 1997; Coffey et al., 1998; Tisserand et al., 2000b, 2002). With respect to white matter lesions, overall sex differences have been reported but no interaction with age (Longstreth et al., 1996; De Groot et al., 2001; De Leeuw et al., 2001), except in one large sample, in which a greater age-related increase in white matter lesions in females was found (Yue et al., 1997). At the functional level, differences between the sexes have been observed. Women were found to have a greater age-related metabolic decline than men in the thalamus and hippocampus (Murphy et al., 1996). However, others have failed to find such sex differences (e.g., Loessner et al., 1995).

In functional activation studies, the effect of sex has received only little attention (save in Nyberg et al., 2000), and to our knowledge, possible interactions between age and sex during task performance have not yet been considered at all. This is a major issue, because different trajectories for age- 
related cognitive decline may exist for healthy men and women (Elias et al., 1997; Laursen, 1997).

Another issue with great importance for the interpretation of age effects on brain structure and function pertains to possible differential decline due to ageextrinsic biomedical factors. The idea that there are various patterns in cognitive ageing trajectories was originally put forward by Rowe and Kahn (1987). These authors distinguished between 'usual' and 'successful' ageing. Successful ageing reflects the situation in which only age-intrinsic factors contribute to a decline in cognitive function. Usual ageing, the most common pattern, is also determined by age-extrinsic factors. For instance, blood pressure increases as a function of age (e.g., Van Boxtel et al., 1996; Rigaud and Forette, 2001), which is of importance as hypertension is associated with abnormalities in cerebral white matter, and both factors have been associated with cognitive decline in older individuals (Skoog, 1994). Furthermore, neurochemical changes occur in the ageing brain, such as decreases in striatal dopaminergic function, and these losses have been associated with cognitive impairments (Volkow et al., 1998; Bäckman et al., 2000; Braver et al., 2001). In addition, long-term exposure to elevated cortisol levels in elderly individuals was found to be related to smaller volume of the hippocampus and impaired performance on memory tests (Lupien et al., 1998). Other age-extrinsic factors which have been associated with cognitive decline include diabetes mellitus, chronic respiratory disease (Van Boxtel et al., 1998), mild sensory impairments (Van Boxtel et al., 2000), and so-called 'biological life events' such as mild brain trauma (Houx et al., 1993; Klein et al., 1996).

Finally, in an attempt to link the issues of sex differences and age-extrinsic factors, it is interesting to consider the effect of steroid hormones on the ageing brain. The interest in the effect that these hormones can exert on the structure and function of the brain has increased now that hormonal replacement therapies have become widespread (e.g., Hogervorst et al., 2000). In particular, the neuroprotective effect of estrogens on the brain (e.g., Sherwin, 1998) may explain attenuation of sex differences in brain volume losses in older individuals (Pruessner et al., 2001). Moreover, estrogen replacement therapy in postmenopausal women has a beneficial effect on brain activity during task performance (Berman et al., 1997; Shaywitz et al., 1999).

Given these findings, it is of importance for cognitive ageing research to acknowledge the possible influence of individual variability due to age-extrinsic factors. In this respect, a dilemma lies within the selection criteria used when sampling healthy older subjects for inclusion in ageing studies: hould they be perfectly healthy (and thus: successfully ageing), or should they be representative for the general elderly population (normally ageing)? Discrepancies between the results of functional imaging studies of cognitive ageing may therefore be due to differences in subject selection criteria.

\section{CONCLUDING REMARKS}

In this paper, we have evaluated current knowledge about structural and functional changes within the ageing brain, and the possible relationship 
between these changes and cognitive decline. Although the neuropsychological literature on the effects of age on cognitive functioning is vast, the application of neuroimaging techniques in this field of research is a relatively recent development. In order to understand the neural mechanisms underlying cognitive ageing much research still has to be conducted. Nevertheless, the close association between ageing, cognition and the frontal lobes has been noted by various authors (e.g., Jolles, 1986; Moscovitch and Winocur, 1995; West, 1996; Phillips and Della Sala, 1999; Braver et al., 2001), and the present review again stresses the importance of the PFC in cognitive ageing. Age-related atrophy is most apparent in this region (e.g., Raz et al., 1997; Tisserand et al., 2002) and the areas to which they are reciprocally connected, i.e., striatum and thalamus (Gunning-Dixon et al., 1998; Van der Werf et al., 2001). In contrast, only moderate volume reductions have been reported within limbic regions (e.g., Raz et al., 1997; Tisserand et al., 2000b). Furthermore, differences between young and older individuals in functional imaging studies, both at rest and during cognitive performance, have been observed most consistently within the frontal lobes (e.g., Loessner et al., 1995; Moeller et al., 1996; Cabeza et al., 1997a, b; Petit-Taboué et al., 1998; Madden et al., 1999; Reuter-Lorenz et al., 2000). Older subjects tend to exhibit a less lateralized activation pattern than their younger counterparts on a variety of tasks (Cabeza, 2002). Nonetheless, it is of importance to note that several researchers have criticized the frontal ageing hypothesis (e.g., Rubin, 1999; Greenwood, 2000; Braver et al., 2001). They have stressed that structural and functional changes also occur in non-frontal regions (Greenwood, 2000; Braver et al., 2001), and that for adequate cognitive functioning the integrity of all the structures involved in that particular function is required (Rubin, 1999). Of course it is untenable to suggest that age-related cognitive impairments exclusively result from prefrontal declines. In fact, we have tried to argue that cognitive impairments should no longer be considered to be the result of structural or functional alterations within one particular brain region. Just as cognitive functions are made up of a number of subprocesses, brain regions are clustered in networks, interconnected by white matter pathways, all of which together allow cognitive processes (Mesulam, 1998; McIntosh, 2000). It seems that disruptions in prefrontal networks, with their specific role in strategic information processing and in modulating neural activity throughout the brain, are crucial for the understanding of age-related cognitive impairments.

Acknowledgements. We thank Jonathan Foster and Marko Jelicic for helpful suggestions on an earlier version of this paper, and the anonymous reviewers for their constructive comments.

\section{REFERENCES}

Abe O, Aoki S, Hayashi N, Yamada H, Kunimatsu A, Mori H et al. Normal aging in the central nervous system: Quantitative MR diffusion- tensor analysis. Neurobiology of Aging, 23: 433-441, 2002.

Alexander GE, Crutcher MD and DeLong MR. Basal ganglia-thalamocortical circuits: Parallel substrates for motor, oculomotor, 'prefrontal' and 'limbic' functions. Progress in Brain Research, 85: 119-146, 1990. 
Anderson ND, Iidaka T, Cabeza R, Kapur S, McIntosh AR and Craik FI. The effects of divided attention on encoding- and retrieval-related brain activity: A PET study of younger and older adults. Journal of Cognitive Neuroscience, 12: 775-792, 2000.

Andreasen NC, O'Leary DS, Arndt S, Cizadlo T, Hurtig R, Rezai K et al. Short-term and long-term verbal memory: A positron emission tomography study. Proceedings of the National Academy of Sciences of the USA, 92: 5111-5115, 1995.

Bäckman L, Almkvist O, Andersson J, Nordberg A, Winblad B, Reineck R et al. Brain activation in young and older adults during implicit and explicit retrieval. Journal of Cognitive Neuroscience, 9: 378-391, 1997.

Bäckman L, Ginovart N, Dixon RA, Wahlin TB, Wahlin A, Halldin C et al. Age-related cognitive deficits mediated by changes in the striatal dopamine system. American Journal of Psychiatry, 157: 635-637, 2000.

Berman KF, Schmidt PJ, Rubinow DR, Danaceau MA, Van Horn JD, Esposito G et al. Modulation of cognition-specific cortical activity by gonadal steroids: A positron-emission tomography study in women. Proceedings of the National Academy of Sciences of the USA, 94: 8836-8841, 1997.

Bigler ED, BlatTer DD, ANDERson AV, Johnson SC, GALE SD, Hopkins RO et al. Hippocampal volume in normal aging and traumatic brain injury. American Journal of Neuroradiology, 18: 11-23, 1997.

Blatter DD, Bigler ED, Gale SD, Johnson SC, Anderson CV, Burnett BM et al. Quantitative volumetric analysis of brain MR: Normative database spanning 5 decades of life. American Journal of Neuroradiology, 16: 241-251, 1995.

Boone KB, Miller BL, Lesser IM, Mehringer CM, Hill-Gutierrez E, Goldberg MA et al. Neuropsychological correlates of white-matter lesions in healthy elderly subjects: A threshold effect. Archives of Neurology, 49: 549-554, 1992.

Braver TS, BArch DM, Keys BA, CARTER CS, Cohen JD, KAYE JA et al. Context processing in older adults: Evidence for a theory relating cognitive control to neurobiology in healthy aging. Journal of Experimental Psychology: General, 130: 746-763, 2001.

Braver TS, Cohen JD, Nystrom LE, Jonides J, Smith EE and Noll DC. A parametric study of prefrontal cortex involvement in human working memory. Neurolmage, 5: 49-62, 1997.

Breteler MM, Van Amerongen NM, Van Swieten JC, Claus JJ, Grobbee DE, Van Gijn J et al. Cognitive correlates of ventricular enlargement and cerebral white matter lesions on magnetic resonance imaging. The Rotterdam Study. Stroke, 25: 1109-1115, 1994.

CABEZA R. Functional neuroimaging of cognitive aging. In R Cabeza and A Kingstone (Eds), Handbook of functional neuroimaging of cognition. Cambridge, MA: MIT Press, 2000, Ch. 10, pp. 331-377.

CABEZA R. Hemispheric asymmetry reduction in older adults: The HAROLD model. Psychology and Aging, 17: 85-100, 2002.

Cabeza R, Anderson ND, Houle S, Mangels JA and Nyberg L. Age-related differences in neural activity during item and temporal-order memory retrieval: A positron emission tomography study. Journal of Cognitive Neuroscience, 12: 197-206, 2000.

Cabeza R, Grady CL, Nyberg L, McIntosh AR, Tulving E, Kapur S et al. Age-related differences in neural activity during memory encoding and retrieval: A positron emission tomography study. Journal of Neuroscience, 17: 391-400, 1997a.

Cabeza R, McIntosh AR, Tulving E, Nyberg L and Grady CL. Age-related differences in effective neural connectivity during encoding and recall. Neuroreport, 8: 3479-3483, $1997 \mathrm{~b}$.

CAlautTi C, SERRATI C and BARON JC. Effects of age on brain activation during auditory-cued thumbto-index opposition: A positron emission tomography study. Stroke, 32: 139-146, 2001.

COFFEY CE. Anatomical imaging of the aging human brain: Computed Tomography and Magnetic Resonance Imaging. In CE Coffey and JL Cummings (Eds), Textbook of Geriatric Neuropsychiatry. Washington DC: American Psychiatric Press, 1993, Ch. 9, pp. 159-194.

Coffey CE, Lucke JF, Saxton JA, Ratcliff G, Unitas LJ, Billig B et al. Sex differences in brain aging: A quantitative magnetic resonance imaging study. Archives of Neurology, 55: 169-179, 1998.

Coffey CE, Wilkinson WE, Parashos IA, Soady SAR, Sullivan RJ, Patterson LJ et al. Quantitative cerebral anatomy of the aging human brain: A cross-sectional study using magnetic resonance imaging. Neurology, 42: 527-536, 1992.

Cohen JD, Perlstein WM, Braver TS, Nystrom LE, Noll DC, Jonides J et al. Temporal dynamics of brain activation during a working memory task. Nature, 386: 604-608, 1997.

Courchesne E, Chisum HJ, Townsend J, Cowles A, Covington J, EgaAs B et al. Normal brain development and aging: Quantitative analysis at in vivo MR imaging in healthy volunteers. Radiology, 216: 672-682, 2000.

Cowell PE, Turetsky BI, Gur RC, Grossman RI, Shtasel DL and Gur RE. Sex differences in aging of the human frontal and temporal lobes. Journal of Neuroscience, 14: 4748-4755, 1994.

CRAIK FIM and BYRD M. Aging and cognitive deficits: The role of attentional resources. In FIM Craik and S Trehub (Eds), Aging and cognitive processes. New York: Plenum, 1982, Ch. 11, pp. 191-211. 
Craik FIM and Jennings JM. Human memory. In FIM Craik and TA Salthouse (Eds), The handbook of aging and cognition. Hillsdale, NJ: Lawrence Erlbaum Associates, 1992, Ch. 2, pp. 51-110.

CuMmings JL. Frontal-subcortical circuits and human behavior. Archives of Neurology, 50: 873-880, 1993.

Cummings JL. Anatomic and behavioral aspects of frontal-subcortical circuits. Annals of the New York Academy of Sciences, 769: 1-13, 1995.

D'Esposito M, Aguirre GK, Zarahn E, Ballard D, Shin RK and Lease J. Functional MRI studies of spatial and nonspatial working memory. Cognitive Brain Research, 7: 1-13, 1998.

D'Esposito M, Zarahn E, AgUiRRE GK and RYPMA B. The effect of normal aging on the coupling of neural activity to the bold hemodynamic response. NeuroImage, 10: 6-14, 1999.

De Groot JC, De Leeuw FE, Oudkerk M, Hofman A, Jolles J and Breteler MM. Cerebral white matter lesions and subjective cognitive dysfunction: The Rotterdam Scan Study. Neurology, 56: 1539-1545, 2001.

De Groot JC, De Leeuw FE, Oudkerk M, van Gijn J, Hofman A, Jolles J et al. Cerebral white matter lesions and cognitive function: The Rotterdam Scan Study. Annals of Neurology, 47: 145$151,2000$.

De Leeuw FE, De Groot JC, Achten E, Oudkerk M, Ramos LM, Heijboer R et al. Prevalence of cerebral white matter lesions in elderly people: A population based magnetic resonance imaging study. The Rotterdam Scan Study. Journal of Neurology, Neurosurgery and Psychiatry, 70: 9-14, 2001.

De Leon MJ, George AE, Golomb J, Tarshish C, Convit A, Kluger A et al. Frequency of hippocampal formation atrophy in normal aging and Alzheimer's disease. Neurobiology of Aging, 18: 1-11, 1997.

De Leon MJ, George AE, Stylopoulos LA, Smith G and Miller DC. Early marker for Alzheimer's disease: The atrophic hippocampus. Lancet, 2: 672-673, 1989.

De Leon MJ, George AE, Tomanelli J, Christman D, Kluger A, Miller J et al. Positron emission tomography studies of normal aging: A replication of PET III and 18-FDG using PET VI and 11CDG. Neurobiology of Aging, 8: 319-323, 1987.

DeCarli C, Murphy DGM, Gillette JA, Haxby JV, Teichberg D, Schapiro MB et al. Lack of agerelated differences in temporal lobe volume of very healthy adults. American Journal of Neuroradiology, 15: 689-696, 1994.

DeCarli C, Murphy DG, Tranh M, Grady CL, Haxby JV, Gillette JA et al. The effect of white matter hyperintensity volume on brain structure, cognitive performance, and cerebral metabolism of glucose in 51 healthy adults. Neurology, 45: 2077-2084, 1995.

Della-Maggiore V, Sekuler AB, Grady CL, Bennett PJ, Sekuler R and McIntosh AR. Corticolimbic interactions associated with performance on a short-term memory task are modified by age. Journal of Neuroscience, 20: 8410-8416, 2000.

EARLES JL, CONNOR LT, SMITH AD and PARK DC. Interrelations of age, self-reported health, speed, and memory. Psychology and Aging, 12: 675-683, 1997.

Elias MF, Elias PK, D’Agostino RB, Silbershatz H and Wolf PA. Role of age, education, and gender on cognitive performance in the Framingham Heart Study: Community-based norms. Experimental Aging Research, 23: 201-235, 1997.

Elliott R, Dolan RJ and Frith CD. Dissociable functions in the medial and lateral orbitofrontal cortex: Evidence from human neuroimaging studies. Cerebral Cortex, 10: 308-317, 2000.

Esposito G, Kirkby BS, Van Horn JD, Ellmore TM and Berman KF. Context-dependent, neural system-specific neurophysiological concomitants of ageing: Mapping PET correlates during cognitive activation. Brain, 122: 963-979, 1999.

FLETCHER PC and HenSON RN. Frontal lobes and human memory: Insights from functional neuroimaging. Brain, 124: 849-881, 2001.

Fletcher PC, Shallice T and Dolan RJ. The functional roles of prefrontal cortex in episodic memory. I. Encoding. Brain, 121: 1239-1248, 1998.

Foster JK, Meikle A, Goodson G, Mayes AR, Howard M, Sunram Si et al. The hippocampus and delayed recall: Bigger is not necessarily better? Memory, 7: 715-732, 1999.

Fox NC, Warrington EK, Freeborough PA, Hartikainen P, Kennedy AM, Stevens JM et al. Presymptomatic hippocampal atrophy in Alzheimer's disease. A longitudinal MRI study. Brain, 119: 2001-2007, 1996.

FUSTER JM. The prefrontal cortex: Anatomy, physiology, and neuropsychology of the frontal lobe. New York: Raven Press, 1980.

Garavan H, Kelley D, Rosen A, Rao SM and Stein EA. Practice-related functional activation changes in a working memory task. Microscopy Research and Technique, 51: 54-63, 2000.

Garraux G, Salmon E, Degueldre C, Lemaire C, Laureys S and Franck G. Comparison of impaired subcortico-frontal metabolic networks in normal aging, subcortico-frontal dementia, and cortical frontal dementia. NeuroImage, 10: 149-162, 1999.

Golomb J, Kruger A, De Leon MJ, Ferris SH, Convit A, Mittelman MS et al. Hippocampal 
formation size in normal human aging: A correlate of delayed secondary memory performance. Learning and Memory, 1: 45-54, 1994.

Golomb J, Kluger A, De Leon MJ, Ferris SH, Mittelman M, Cohen J et al. Hippocampal formation size predicts declining memory performance in normal aging. Neurology, 47: 810-813, 1996.

GRADY CL. Brain imaging and age-related changes in cognition. Experimental Gerontology, 33: 661673, 1998.

GRADY CL. Functional brain imaging and age-related changes in cognition. Biological Psychology, 54: 259-281, 2000.

Grady CL and CRAIK FI. Changes in memory processing with age. Current Opinion in Neurobiology, 10: 224-231, 2000.

Grady CL, Maisog JM, Horwitz B, Ungerleider LG, Mentis MJ, Salerno JA et al. Age-related changes in cortical blood flow activation during visual processing of faces and location. Journal of Neuroscience, 14: 1450-1462, 1994.

Grady CL, McIntosh AR, Bookstein F, Horwitz B, Rapoport Si and Haxby JV. Age-related changes in regional cerebral blood flow during working memory for faces. NeuroImage, 8: 409-425, 1998a.

Grady CL, Mcintosh AR, Horwitz B, Maisog JM, Ungerleider LG, Mentis MJ et al. Agerelated reductions in human recognition memory due to impaired encoding. Science, 269: 218-221, 1995.

Grady CL, McIntosh AR, RAJAh MN and CRAIK FI. Neural correlates of the episodic encoding of pictures and words. Proceedings of the National Academy of Sciences of the USA, 95: 2703-2708, 1998b.

GRAF P and SCHACTER DL. Implicit and explicit memory for new associations in normal and amnesic subjects. Journal of Experimental Psychology: Learning, Memory and Cognition, 11: 501-518, 1985.

GREENwood PM. The frontal aging hypothesis evaluated. Journal of the International Neuropsychological Society, 6: 705-726, 2000.

Gunning-Dixon FM, HeAd D, MCQuAin J, ACKER JD and RAZ N. Differential aging of the human striatum: A prospective MR imaging study. American Journal of Neuroradiology, 19: 1501-1507, 1998.

GunNING-DiXON FM and RAZ N. The cognitive correlates of white matter abnormalities in normal aging: A quantitative review. Neuropsychology, 14: 224-232, 2000.

Gur RC, Mozley PD, Resnick SM, GotTlieb GL, Kohn M, Zimmerman R et al. Gender differences in age effect on brain atrophy measured by magnetic resonance imaging. Proceedings National Academy of Sciences of the USA, 88: 2845-2849, 1991.

Gur RC, Turetsky BI, Matsui M, Yan M, Bilker W, Hughett P et al. Sex differences in brain gray and white matter in healthy young adults: Correlations with cognitive performance. Journal of Neuroscience, 19: 4065-4072, 1999.

Guttmann CR, Jolesz FA, Kikinis R, Killiany RJ, Moss MB, Sandor T et al. White matter changes with normal aging. Neurology, 50: 972-978, 1998.

Hänninen T, Hallikainen M, Koivisto K, PARTANEN K, LAakso MP, RieKKinen PJ Sr et al. Decline of frontal lobe functions in subjects with age-associated memory impairment. Neurology, 48: 148-153, 1997.

HASHER L and ZACKS RT. Working memory, comprehension and aging: A review and a new view. Psychology of Learning and Motivation, 22: 193-225, 1988.

HAUG H. Are neurons of the human cerebral cortex really lost during aging? A morphometric examination. In J Traber and WH Gispen (Eds), Senile dementia of the Alzheimer type. New York: Springer-Verlag, 1985, pp. 150-163.

Hogervorst E, Williams J, Budge M, Riedel W and Jolles J. The nature of the effect of female gonadal hormone replacement therapy on cognitive function in post-menopausal women: A metaanalysis. Neuroscience, 101: 485-512, 2000.

Horwitz B, McIntosh AR, Haxby JV, Furey M, Salerno JA, Schapiro MB et al. Network analysis of PET-mapped visual pathways in Alzheimer type dementia. Neuroreport, 6: 2287-2292, 1995.

Houx PJ, Jolles J and VReELING FW. Stroop interference: Aging effects assessed with the Stroop ColorWord Test. Experimental Aging Research, 19: 209-224, 1993.

JACK CR, JR., PETERSEN RC, O'BRIEN PC and TANGAlos EG. MR-based hippocampal volumetry in the diagnosis of Alzheimer's disease. Neurology, 42: 183-188, 1992.

Jack CR, JR., Petersen RC, Xu Y, O’Brien PC, Smith GE, Ivnik RJ et al. Rate of medial temporal lobe atrophy in typical aging and Alzheimer's disease. Neurology, 51: 993-999, 1998.

JACK CR, JR, PETERSEN RC, XU YC, O'BRIEN PC, SMITH GE, IVNIK RJ et al. Prediction of AD with MRIbased hippocampal volume in mild cognitive impairment. Neurology, 52: 1397-1403, 1999.

JANOWSKy JS, Shimamura AP, KRITCheVsky M and SQUIRE LR. Cognitive impairment following frontal lobe damage and its advance to human amnesia. Behavioral Neuroscience, 103: 548-560, 1989. 
JANSMA JM, RAMSEY NF, SLAGTER HA and KAHN RS. Functional anatomical correlates of controlled and automatic processing. Journal of Cognitive Neuroscience, 13: 730-743, 2001.

Jernigan TL, Archibald SL, Berhow MT, Sowell ER, Foster DS and Hesselink JR. Cerebral structure on MRI, Part I: Localization of age-related changes. Biological Psychiatry, 29: 55-67, 1991.

Jernigan TL, Archibald SL, Fennema-Notestine C, Gamst AC, Stout JC, Bonner J et al. Effects of age on tissues and regions of the cerebrum and cerebellum. Neurobiology of Aging, 22: 581-594, 2001.

Johannsen P, Jakobsen J, Bruhn P, Hansen SB, Gee A, Stodkilde-Jorgensen H et al. Cortical sites of sustained and divided attention in normal elderly humans. NeuroImage, 6: 145-155, 1997.

Jolles J. Cognitive, emotional and behavioral dysfunctions in aging and dementia. Progress in Brain Research, 70: 15-39, 1986.

KabAni NJ, SLed JG and ChertKow H. Magnetization transfer ratio in mild cognitive impairment and dementia of Alzheimer's type. NeuroImage, 15: 604-610, 2002.

Kapur S, Tulving E, Cabeza R, McIntosh AR, Houle S and Craik FI. The neural correlates of intentional learning of verbal materials: A PET study in humans. Cognitive Brain Research, 4: 243 249, 1996.

Kaye JA, Swihart T, Howieson D, Dame A, Moore MM, Karnos T et al. Volume loss of the hippocampus and temporal lobe in healthy elderly persons destined to develop dementia. Neurology, 48: 1297-1304, 1997.

KEMPER TL. Neuroanatomical and neuropathological changes during aging and in dementia. In ML Albert and EJE Knoepfel (Eds), Clinical neurology of aging. New York: Oxford University Press, 1994, Ch. 1, pp. 3-67.

Kirasic KC, Allen GL, Dobson SH and Binder KS. Aging, cognitive resources, and declarative learning. Psychology and Aging, 11: 658-670, 1996.

KLEIN M, HouX PJ and JOLLES J. Long-term persisting cognitive sequelae of traumatic brain injury and the effect of age. Journal of Mental and Nervous Disease, 184: 459-467, 1996.

Köhler S, Black SE, Sinden M, Szekely C, Kidron D, Parker JL et al. Memory impairments associated with hippocampal versus parahippocampal-gyrus atrophy: An MR volumetry study in Alzheimer's disease. Neuropsychologia, 36: 901-914, 1998.

Kopelman MD, Stevens TG, Foli S and Grasby P. PET activation of the medial temporal lobe in learning. Brain, 121: 875-887, 1998.

Kuhl DE, MetTer EJ, RIEge WH and Phelps ME. Effects of human aging on patterns of local cerebral glucose utilization determined by the [18F]fluorodeoxyglucose method. Journal of Cerebral Blood Flow and Metabolism, 2: 163-171, 1982.

Laakso MP, Hallikainen M, Hanninen T, Partanen K and Soininen H. Diagnosis of Alzheimer's disease: MRI of the hippocampus vs delayed recall. Neuropsychologia, 38: 579-584, 2000.

LAURSEN P. The impact of aging on cognitive functions. An 11-year follow-up study of four age cohorts. Acta Neurologica Scandinavica Supplement, 172: 7-86, 1997.

Leenders KL, Perani D, Lammertsma AA, Heather JD, Buckingham P, Healy MJ et al. Cerebral blood flow, blood volume and oxygen utilization. Normal values and effect of age. Brain, 113: 27 47, 1990.

Lim KO, Zipursky RB, Murphy GMJ and Pfefferbaum A. In vivo quantification of the limbic system using MRI: Effects of normal aging. Psychiatry Research: Neuroimaging, 35: 15-26, 1990.

Loessner A, Alavi A, Lewandrowski KU, Mozley D, Souder E and Gur RE. Regional cerebral function determined by FDG-PET in healthy volunteers: normal patterns and changes with age. Journal of Nuclear Medecine, 36: 1141-1149, 1995.

Longstreth WT, Jr, Manolio TA, Arnold A, Burke GL, Bryan N, Jungreis CA et al. Clinical correlates of white matter findings on cranial magnetic resonance imaging of 3301 elderly people. The Cardiovascular Health Study. Stroke, 27: 1274-1282, 1996.

Lupien SJ, de Leon M, DE SAnti S, Convit A, TARshish C, NAir NP et al. Cortisol levels during human aging predict hippocampal atrophy and memory deficits. Nature Neuroscience, 1: 69-73, 1998.

Madden DJ, Turkington TG, Provenzale JM, Denny Ll, Hawk TC, Gottlob LR et al. Adult age differences in the functional neuroanatomy of verbal recognition memory. Human Brain Mapping, 7: $115-135,1999$.

Madden DJ, Turkington TG, Provenzale JM, Hawk TC, Hoffman JM and Coleman RE. Selective and divided visual attention: Age-related changes in regional cerebral blood flow measured by $\mathrm{H} 2$ 15 O PET. Human Brain Mapping, 5: 389-409, 1997.

Manoach DS, Schlaug G, Siewert B, Darby DG, Bly BM, Benfield A et al. Prefrontal cortex fMRI signal changes are correlated with working memory load. Neuroreport, 8: 545-549, 1997.

Martin AJ, Friston KJ, Colebatch JG and Frackowiak RSJ. Decreases in regional cerebral blood flow with normal aging. Journal of Cerebral Blood Flow and Metabolism, 11: 684-689, 1991.

McInTosh AR. Mapping cognition to the brain through neural interactions. Memory, 7: 523-548, 1999. 
McIntosh AR. Towards a network theory of cognition. Neural Networks, 13: 861-870, 2000.

McIntosh AR, Sekuler AB, Penpeci C, Rajah MN, Grady CL, SeKuler R et al. Recruitment of unique neural systems to support visual memory in normal aging. Current Biology, 9: 1275-1278, 1999.

Mencl We, Pugh KR, Shaywitz SE, Shaywitz BA, Fulbright RK, Constable RT et al. Network analysis of brain activations in working memory: Behavior and age relationships. Microscopy Research and Technique, 51: 64-74, 2000.

Mesulam MM. From sensation to cognition. Brain, 121: 1013-1052, 1998.

Mitchell KJ, Johnson MK, RAYE CL and D'EsPosito M. fMRI evidence of age-related hippocampal dysfunction in feature binding in working memory. Cognitive Brain Research, 10: 197-206, 2000.

Moeller JR, Ishikawa T, Dhawan V, Spetsieris P, Mandel F, Alexander GE et al. The metabolic topography of normal aging. Journal of Cerebral Blood Flow and Metabolism, 16: 385398, 1996.

MorRISON JH and HoF PR. Life and death of neurons in the aging brain. Science, 278: 412-419, 1997.

Moscovitch M and Winocur G. The neuropsychology of memory and aging. In FIM Craik and TA Salthouse (Eds.), The handbook of aging and cognition. Hillsdale: Lawrence Erlbaum Associates, 1992, Ch. 7, pp. 315-372.

Moscovitch M and Winocur G. Frontal lobes, memory, and aging. Annals of the New York Academy of Sciences, 769: 119-150, 1995.

Mueller EA, Moore MM, Kerr DC, Sexton G, Camicioli RM, Howieson DB et al. Brain volume preserved in healthy elderly through the eleventh decade. Neurology, 51: 1555-1562, 1998.

Murphy DG, DeCarli C, McIntosh AR, Daly E, Mentis MJ, Pietrini P et al. Sex differences in human brain morphometry and metabolism: An in vivo quantitative magnetic resonance imaging and positron emission tomography study on the effect of aging. Archives of General Psychiatry, 53: 585594, 1996.

Nagahama Y, Fukuyama H, Yamauchi H, Katsumi Y, Magata Y, Shibasaki H et al. Age-related changes in cerebral blood flow activation during a Card Sorting Test. Experimental Brain Research, 114: 571-577, 1997.

Nolde SF, Johnson MK and RAYE CL. The role of prefrontal cortex during tests of episodic memory. Trends in Cognitive Sciences, 2: 399-406, 1998.

Nusbaum AO, Tang CY, Buchsbaum MS, Wei TC and Atlas SW. Regional and global changes in cerebral diffusion with normal aging. American Journal of Neuroradiology, 22: 136-142, 2001.

NyBerg L, HabiB R and Herlitz A. Brain activation during episodic memory retrieval: Sex differences. Acta Psychologica, 105: 181-194, 2000.

Nyberg L, Mcintosh AR, Cabeza R, Habib R, Houle S, and Tulving E. General and specific brain regions involved in encoding and retrieval of events: What, where, and when? Proceedings of the National Academy of Sciences of the USA, 93: 11280-11285, 1996a.

Nyberg L, McIntosh AR, Cabeza R, Nilsson LG, Houle S, Habib R et al. Network analysis of positron emission tomography regional cerebral blood flow data: Ensemble inhibition during episodic memory retrieval. Journal of Neuroscience, 16: 3753-3759, $1996 \mathrm{~b}$.

O’Sullivan M, Jones DK, Summers PE, Morris RG, Williams SC and Markus HS. Evidence for cortical "disconnection" as a mechanism of age-related cognitive decline. Neurology, 57: 632-638, 2001.

Owen AM, Evans AC, and Petrides M. Evidence for a two-stage model of spatial working memory processing within the lateral frontal cortex: A positron emission tomography study. Cerebral Cortex, 6: 31-38, 1996.

Owen AM, Stern CE, Look RB, Tracey I, Rosen BR and Petrides M. Functional organization of spatial and nonspatial working memory processing within the human lateral frontal cortex. Proceedings of the National Academy of Sciences of the USA, 95: 7721-7726, 1998.

Park DC, Smith AD, Lautenschlager G, EARles JL, Frieske D, Zwahr M et al. Mediators of longterm memory performance across the life span. Psychology and Aging, 11: 621-637, 1996.

PARKIN AJ and JAVA RI. Determinants of age-related memory loss. In TJ Perfect and EA Maylor (Eds), Models of cognitive aging. Oxford: University Press, 2000, Ch. 7, pp. 188-203.

Petersen RC, JACK CR, JR., Xu YC, WARING SC, O'Brien PC, SMith GE et al. Memory and MRIbased hippocampal volumes in aging and AD. Neurology, 54: 581-587, 2000.

Petit-Taboué MC, Landeau B, Desson JF, Desgranges B and Baron JC. Effects of healthy aging on the regional cerebral metabolic rate of glucose assessed with statistical parametric mapping. NeuroImage, 7: 176-184, 1998.

Petri HL and Mishrin M. Behaviorism, cognitivism and the neuropsychology of memory. American Scientist, 82: 30-37, 1994.

PETRIDES M. Functional organization of the human frontal cortex for mnemonic processing. Evidence from neuroimaging studies. Annals of the New York Academy of Sciences, 769: 85-96, 1995.

Pfefferbaum A, Mathalon DH, Sullivan EV, Rawles JM, Zipursky RB and Lim KO. A quantitative magnetic resonance imaging study of changes in brain morphology from infancy to late adulthood. Archives of Neurology, 51: 874-887, 1994. 
Pfefferbaum A, Sullivan EV, Rosenbloom MJ, Mathalon DH, and Lim KO. A controlled study of cortical gray matter and ventricular changes in alcoholic men over a 5-year interval. Archives of General Psychiatry, 55: 905-912, 1998.

Phillips LH and Della Sala S. Aging, intelligence, and anatomical segregation in the frontal lobes. Learning and Individual Differences, 10: 217-243, 1999.

Pierpaoli C, Jezzard P, Basser PJ, Barnett A and Di Chiro G. Diffusion tensor MR imaging of the human brain. Radiology, 201: 637-648, 1996.

Pruessner JC, Collins DL, Pruessner M and Evans AC. Age and gender predict volume decline in the anterior and posterior hippocampus in early adulthood. Journal of Neuroscience, 21: 194-200, 2001.

Prull MW, Gabrieli JDE and Bunge SA. Age-related changes in memory: A cognitive neuroscience perspective. In FIM Craik and TA Salthouse (Eds), The handbook of aging and cognition. Mahwah, NJ: Lawrence Erlbaum Associates, 2000, Ch. 2, pp. 91-154.

Raichle ME, Fiez JA, VideEn TO, MacLeod AM, PARdo JV, Fox PT et al. Practice-related changes in human brain functional anatomy during nonmotor learning. Cerebral Cortex, 4: 8-26, 1994.

Raz N. Aging of the brain and its impact on cognitive performance: Integration of structural and functional findings. In FIM Craik and TA Salthouse (Eds), The handbook of aging and cognition. Mahwah: Lawrence Erlbaum Associates, 2000, Ch. 1, pp. 1-90.

Raz N, Gunning FM, Head D, Dupuis JH, McQuain J, BRIGGS SD et al. Selective aging of the human cerebral cortex observed in vivo: Differential vulnerability of the prefrontal gray matter. Cerebral Cortex, 7: 268-282, 1997.

Raz N, Gunning-DiXon FM, HeAd D, Dupuis JH and ACKer JD. Neuroanatomical correlates of cognitive aging: Evidence from structural magnetic resonance imaging. Neuropsychology, 12: 95$114,1998$.

RAZ N, TORRES IJ and ACKER JD. Age-related shrinkage of the mamillary bodies: In vivo MRI evidence. Neuroreport, 3: 713-716, 1992.

Resnick SM, Goldszal AF, Davatzikos C, Golski S, Kraut MA, Metter EJ et al. One-year age changes in MRI brain volumes in older adults. Cerebral Cortex, 10: 464-472, 2000.

Reuter-Lorenz PA, Jonides J, Smith EE, Hartley A, Miller A, Marshuetz C et al. Age differences in the frontal lateralization of verbal and spatial working memory revealed by PET. Journal of Cognitive Neuroscience, 12: 174-187, 2000.

Rigaud AS and ForeTte B. Hypertension in older adults. Journal of Gerontology, 56: M217-225, 2001.

Ross MH, Yurgelun-Todd DA, Renshaw PF, Maas LC, Mendelson JH, Mello NK et al. Age-related reduction in functional MRI response to photic stimulation. Neurology, 48: 173-176, 1997.

Rowe JW and KaHN RL. Human aging: Usual and successful. Science, 237: 143-149, 1987.

RUBIN DC. Frontal-striatal circuits in cognitive aging: Evidence for caudate involvement. Aging, Neuropsychology, and Cognition, 6: 241-259, 1999.

Rugg MD, Fletcher PC, Frith CD, Frackowiak RS and Dolan RJ. Brain regions supporting intentional and incidental memory: A PET study. Neuroreport, 8: 1283-1287, 1997.

RYPMA B and D'Esposito M. The roles of prefrontal brain regions in components of working memory: Effects of memory load and individual differences. Proceedings of the National Academy of Sciences of the USA, 96: 6558-6563, 1999.

RYPMA B and D'Esposito M. Isolating the neural mechanisms of age-related changes in human working memory. Nature Neuroscience, 3: 509-515, 2000.

SALAT DH, KAYE JA and JANOWSKY JS. Prefrontal gray and white matter volumes in healthy aging and Alzheimer disease. Archives of Neurology, 56: 338-344, 1999.

SALAT DH, KAYE JA and JANOWSKY JS. Selective preservation and degeneration within the prefrontal cortex in aging and Alzheimer disease. Archives of Neurology, 58: 1403-1408, 2001.

SALTHOUSE TA. The processing-speed theory of adult age differences in cognition. Psychological Review, 103: 403-428, 1996.

Schacter DL, Buckner RL, Koutstaal W, Dale AM and Rosen BR. Late onset of anterior prefrontal activity during true and false recognition: An event-related fMRI study. NeuroImage, 6: 259-269, 1997.

Schacter DL, Savage CR, Alpert NM, Rauch SL and Albert MS. The role of hippocampus and frontal cortex in age-related memory changes: A PET study. Neuroreport, 7: 1165-1169, 1996.

Schultz SK, O’Leary DS, Boles Ponto LL, Watkins GL, Hichwa RD and Andreasen NC. Agerelated changes in regional cerebral blood flow among young to mid-life adults. Neuroreport, 10 : 2493-2496, 1999.

Shaywitz SE, Shaywitz BA, Pugh KR, Fulbright RK, Skudlarski P, Mencl WE et al. Effect of estrogen on brain activation patterns in postmenopausal women during working memory tasks. Journal of the American Medical Association, 281: 1197-1202, 1999.

SHERWIN BB. Estrogen and cognitive functioning in women. Proceedings of the Society for Experimental Biology and Medicine, 217: 17-22, 1998. 
Shimamura AP, Jurica PJ, Mangels JA, Gershberg FB and Knight RT. Susceptibility to memory interference effects following frontal lobe damage: Findings from tests of paired-associated learning. Journal of Cognitive Neuroscience, 7: 144-152, 1995.

Skoog I. Risk factors for vascular dementia: A review. Dementia, 5: 137-144, 1994.

Smith Ee, Geva A, Jonides J, Miller A, Reuter-Lorenz P and Koeppe RA. The neural basis of taskswitching in working memory: Effects of performance and aging. Proceedings of the National Academy of Sciences of the USA, 98: 2095-2100, 2001.

SMith EE and JonIDES J. Working memory: A view from neuroimaging. Cognitive Psychology, 33: 542, 1997.

SMith EE and Jonides J. Storage and executive processes in the frontal lobes. Science, 283: 1657-1661, 1999.

Smith EE, Jonides J and KoEpre RA. Dissociating verbal and spatial working memory using PET. Cerebral Cortex, 6: 11-20, 1996.

Stern CE, Owen AM, Tracey I, Look RB, Rosen BR and Petrides M. Activity in ventrolateral and mid-dorsolateral prefrontal cortex during nonspatial visual working memory processing: Evidence from functional magnetic resonance imaging. NeuroImage, 11: 392-399, 2000.

Stuss DT, Alexander MPM, Palumbo CL, Buckle L, Sayer L and Pogue EJ. Organizational strategies of patients with unilateral or bilateral frontal lobe injury in word list learning. Neuropsychology, 8: 355-373, 1994.

Stuss DT and BENSON DF. The frontal lobes. New York: Raven Press, 1986.

Sullivan EV, Adalsteinsson E, Hedehus M, Ju C, Moseley M, LiM KO et al. Equivalent disruption of regional white matter microstructure in ageing healthy men and women. Neuroreport, 12: 99-104, 2001 .

Sullivan EV, Lane B, Deshmukh A, Rosenbloom MJ, Desmond JE, Lim KO et al. In vivo mammillary body volume deficits in amnesic and nonamnesic alcoholics. Alcoholism: Clinical and Experimental Research, 23: 1629-1636, 1999.

Sullivan EV, Marsh L, Mathalon DH, Lim KO and Pfefferbaum A. Age-related decline in MRI volumes of temporal lobe gray matter but not hippocampus. Neurobiology of Aging, 16: 591-606, 1995.

Tisserand DJ, Pruessner JC, Sanz Arigita EJ, Van Boxtel MPJ, Evans AC, Jolles J and Uylings HBM. Regional frontal cortical volumes decrease differentially in aging: An MRI study to compare volumetric approaches and voxel-based morphometry. NeuroImage, 17: 657-669, 2002.

TISSERAND DJ, RIEDEL WJ and BACKes WH. Differentiating between slope and intercept activity during Sternberg's memory search task using fMRI. European Journal of Neuroscience, 12: 200, 2000a.

Tisserand D, Van Boxtel M, Gronenschild E and Jolles J. Age-related volume reductions of prefrontal regions in healthy individuals are differential. Brain and Cognition, 47: 182-185, 2001.

Tisserand DJ, Visser PJ, Boxtel MPJv and Jolles J. The relation between global and limbic brain volumes on MRI and cognitive performance in healthy individuals across the age range. Neurobiology of Aging, 21: 569-576, 2000b.

Tulving E, Kapur S, Craik FI, Moscovitch M and Houle S. Hemispheric encoding/retrieval asymmetry in episodic memory: Positron emission tomography findings. Proceedings of the National Academy of Sciences of the USA, 91: 2016-2020, 1994.

Uylings HBM, West MJ, Coleman PD, De Brabander JM and Flood DG. Neuronal and cellular changes in the aging brain. In CM Clark and JQ Trojanowski (Eds), Neurodegenerative dementias. New York: McGraw-Hill, 2000, Ch. 4, pp. 61-76.

Van Boxtel MP, Buntinx F, Houx PJ, Metsemakers JF, Knottnerus A and Jolles J. The relation between morbidity and cognitive performance in a normal aging population. Journal of Gerontology, 53: M147-154, 1998.

VAn Boxtel MP, Van Beijsterveldt CE, Houx PJ, Anteunis LJ, Metsemakers JF and Jolles J. Mild hearing impairment can reduce verbal memory performance in a healthy adult population. Journal of Clinical and Experimental Neuropsychology, 22: 147-154, 2000.

Van Boxtel MPJ, Gaillard C, Van Es PN, Jolles J and De Leeuw PW. Repeated automatic versus ambulatory blood pressure measurement: The effects of age and sex in a normal aging population. Journal of Hypertension, 14: 31-40, 1996.

VAN DER Werf YD, Tisserand DJ, VisSER PJ, Hofman PA, VuURman E, Uylings HB et al. Thalamic volume predicts performance on tests of cognitive speed and decreases in healthy aging. A magnetic resonance imaging-based volumetric analysis. Cognitive Brain Research, 11: 377-385, 2001.

Verhaeghen P, MARCoEn A and Goossens L. Facts and fiction about memory aging: A quantitative integration of research findings. Journal of Gerontology, 48: 157-171, 1993.

Visser PJ, Scheltens P, Verhey FR, Schmand B, Launer LJ, Jolles J et al. Medial temporal lobe atrophy and memory dysfunction as predictors for dementia in subjects with mild cognitive impairment. Journal of Neurology, 246: 477-485, 1999. 
Volkow ND, Gur RC, Wang GJ, Fowler JS, Moberg PJ, Ding YS et al. Association between decline in brain dopamine activity with age and cognitive and motor impairment in healthy individuals. American Journal of Psychiatry, 155: 344-349, 1998.

Wagner AD, Desmond JE, Glover GH and Gabrieli JD. Prefrontal cortex and recognition memory. Functional-MRI evidence for context-dependent retrieval processes. Brain, 121: 19852002, 1998.

WeSt RL. An application of prefrontal cortex function theory to cognitive aging. Psychological Bulletin, 120: 272-292, 1996.

Xu J, Kobayashi S, Yamaguchi S, Iijima K, OKada K and Yamashita K. Gender effects on age-related changes in brain structure. American Journal of Neuroradiology, 21: 112-118, 2000.

Ylikoski R, Salonen O, Mantyla R, Ylikoski A, KeskivaAra P, Leskela M et al. Hippocampal and temporal lobe atrophy and age-related decline in memory. Acta Neurologica Scandinavica, 101: 273-278, 2000.

Ylikoski R, Ylikoski A, ERKinjuntti T, Sulkava R, Raininko R and Tilvis R. White matter changes in healthy elderly persons correlate with attention and speed of mental processing. Archives of Neurology, 50: 818-824, 1993.

Yue NC, Arnold AM, Longstreth WT Jr, Elster AD, Jungreis CA, O'Leary DH et al. Sulcal, ventricular, and white matter changes at MR imaging in the aging brain: Data from the cardiovascular health study. Radiology, 202: 33-39, 1997.

ZACKS RT, HASHER L and LI KZH. Human memory. In FIM Craik and TA Salthouse (Eds), The handbook of aging and cognition. Mahwah, NJ: Lawrence Erlbaum Associates, 2000, Ch. 5, pp. 293-358.

Zola-Morgan S and SQuire LR. Neuroanatomy of memory. Annual Review of Neuroscience, 16: 547$563,1993$.

D.J. Tisserand, Rotman Research Institute, Baycrest Centre for Geriatric Care, 3560 Bathrust Street, Toronto, Ontario MGA 2 E1. e-mail: dtisserand@rotman-baycrest.on.ca 